\title{
A Radiation of Hydrobiid Snails in Threatened Artesian Springs in Western Queensland
}

\author{
W.F. Ponder \& G.A. Clark
}

Australian Museum

PO Box A285, Sydney South, NSW 2000, Australia

\begin{abstract}
A radiation of hydrobiid snails exhibiting diverse morphology is described from western Queensland. All but one of the species live in springs west of the Great Dividing Range, most of them derived from water emanating from the Great Artesian Basin. Twelve species contained in the genus Jardinella are described from eight springs or small spring groups, spread over an area of about $260,850 \mathrm{~km}^{2}$. Most of the species are found in springs that are highly vulnerable to damage and are thus under threat of extinction. Only one species is located in a protected area. The 12 species, all of them new, are discriminated primarily using shell and anatomical characters. A cladistic analysis is used to indicate the probable evolution of the group which is shown to be a monophyletic radiation separated from related genera on opercular and genital morphology. Discriminate analysis shows that the species can be distinguished on shell characters alone. Seven allopatric species are found in separate springs or small groups of springs, the remaining five (and a sixth undescribed species) live in Edgbaston Springs, all six species living sympatrically in at least one of these springs. The genus Jardinella is thought to consist of the relictual endpoints of a radiation that commenced in the (mid?)Tertiary. The type species is found in coastal streams and rivers in north Queensland and represents a rather derived member of the group. All but one of the spring-associated species is considered to be endangered because the springs in which they are found have no conservation status and are threatened by pastoral activities and drawdown caused by artesian bores.
\end{abstract}

PONDER, W.F. \& G.A. ClARK, 1990. A radiation of hydrobiid snails in threatened artesian springs in western Queensland. Records of the Australian Museum 42(3): 301-363.

\section{Contents}

Introduction

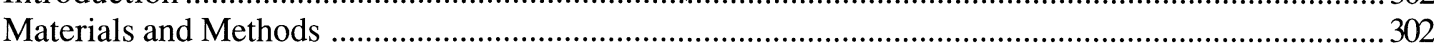

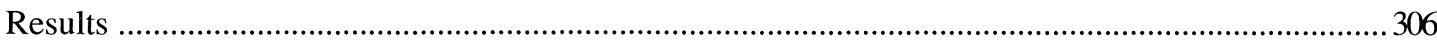

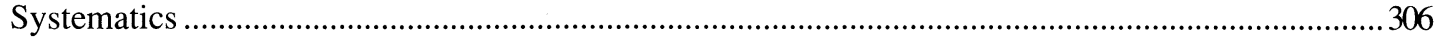

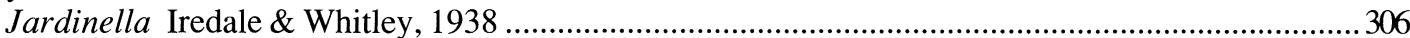

